\title{
WATER QUALITY NETWORK BRIDGING REGULATION, TECHNOLOGY AND SOCIETY IN BRAZIL
}

\author{
VERA MARIA LOPS PONÇANO \& GUILHERME ARY PLONSKI \\ Network of Sanitation and Water Supply, Sibratec, \\ Ministry of Science, Technology, Innovation and Communication, Brazil
}

\begin{abstract}
Water is one of the key resources for life. Its composition - based on reliable laboratory results, like physical, chemical and microbiology analysis - is essential for assessing its quality. Nowadays, society is much more aware about water value, and quality water is a global concern. It poses risks in different ways, like microbiological, chemical and physical forms, and is part of the Sustainable Development Agenda to be achieved by 2030: item 6 "Ensure access to water and sanitation for all". Many actions were taken to preserve this necessity; looking for ways to improve culture and systems and minimizing threats. Water-related matters become increasingly important and attractive to Brazilian society: calling people's attention, media coverage and political decisions, with subsequent regulations like those for drinking water (Ordinance 2914:2011). The national Water Supply and Sanitation Network (RESAG) was created in 2011 as part of the Brazilian Technology System (Sibratec), established by the Ministry of Science Technology Innovation and Communication. Its objective is developing technology and innovation to meet market demands, by means of competent laboratories to support decision makers, mainly in the health and environment areas. For consolidation of the RESAG structure, it was organized as a network system, comprising of 37 laboratories of 19 institutions from 10 Brazilian States, covering the North, Northeast, South and Southeast regions. Currently, its structure involves 310 researchers and technicians that are developing projects on management, training, analytical competence, accreditation, proficiency testing, certified reference materials production, calibration, and materials for sanitation. Many players are required to cover the area of sanitation and water supply, which explains why cooperative platforms such as RESAG have demonstrated many beneficial results. Proactive actions and wise policies, legislation and regulation, can make water management more efficient and enable positive results for human well-being, environment, and national economies.
\end{abstract}

Keywords: water, quality, sanitation, drinking water, RESAG, Sibratec, laboratory, technological network.

\section{INTRODUCTION}

Water is a human right and a natural resource essential for life, applied in many areas, like industry, hygiene, food processing and consumption. Water ecosystems have undergone profound changes for years, mainly due to human activities within different sectors, receiving a wide variety and amount of pollutants, by soil or directly discharged into water. Those events cause an impact on both environment and human health. For a long time, the notion of abundance caused a waste of water, lack of quality control, and less protection of water resources.

Nowadays, it is one of the 17 goals to transform our world, specifically it is Goal 6 : "Ensure access to water and sanitation for all"; addressing the efforts from United Nations, government, businesses, and civil society to achieve the Sustainable Development Agenda by 2030 - to improve people's lives everywhere. Nevertheless, billions are still faced with daily challenges accessing even the most basic of services. Around 1.8 billion people globally use a source of drinking water that is fecally contaminated. Some 2.4 billion people lack access to basic sanitation services, such as toilets or latrines. Water scarcity affects more than 40 per cent of the global population, and is projected to rise. More than 80 per cent of wastewater resulting from human activities is discharged into rivers or sea without any 
treatment, leading to pollution. Water and sanitation related diseases remain among the major causes of death in children under five; more than 800 children die every day from diarrheal diseases linked to poor hygiene [1].

It has many uses and benefits but, if not adequate treated, it also poses risks in different ways, like microbiological, chemical and physical forms, showing the need for continuous attention for ensuring water quality and safety.

\subsection{Brazil scenery}

The Federative Republic of Brazil is the world's fifth-largest country, with a population of about 207 million people in a territory of 8,512,000 square kilometers [1], and a privileged position in terms of water resources. Nevertheless, more than $73 \%$ of the fresh water available in Brazil is in the Amazon basin, where less than 5\% of the population live. Only $27 \%$ of Brazilian water resources are available for $95 \%$ of the country's population [2].

In Brazil, water-scarcity-related problems come from different sources, such as high population growth, unplanned urban areas and constructions, industrialization and agriculture, which increase consumption on one hand, and cause water quality degradation on the other. This situation has affected country's economic profile, health, water resources, availability, etc.

In the water resource contamination process, agriculture poses a threat using pesticides and fertilizers that can reach groundwater by infiltrating the soil, or draining directly into rivers with the surface runoff water [3]. However, water contamination in urban areas is mainly due to domestic sewage, which is continuous and highly polluting, and closely associated with the spread of human water-borne diseases. In Brazil, sewage is a major cause of water pollution. Data from a recent study by the World Health Organization shows that in 23 countries, including Brazil, more than $10 \%$ of infant mortality is linked with water contamination [4].

Determination of water quality has been adopted as one of the main criteria for the establishment of water use, because these standards aim, above all, at the consumer population's safety. This is since water quality is not necessarily a state of purity, but it is configured by its chemical, physiological, and biological characteristics [5].

Regarding the social aspects, a high number of poor Brazilians live in urban slums (favelas) and rural areas without access to piped water or sanitation. Beside this, water is scarce in the northeast of Brazil and water pollution is customary, especially in the southeast of the country [6].

Brazilian society is nowadays aware about water value, and many actions have been taken to preserve this necessity, looking for ways to improve culture and systems, and minimizing the threats to water quality. Water-related matters become increasingly important and attractive to Brazilian society, calling people's attention, media coverage and political decisions, with subsequent regulations. This contributes to establish a foundation to build a sustainable development model for this necessary resource.

Brazil has a national system to finance water and sanitation infrastructure. As part of the current policies and regulations, the Ministry of Cities coordinates sector policies that are implemented by various ministries. For example, the Ministry of Health has certain attributions related to sanitation, and the Ministries of Regional Development and Agriculture and Agrarian Reform have attributions in rural areas. Water resource management is the responsibility of the National Water Agency [7]. 


\subsection{Laws and Federal public administration}

Federal Law \# 9.433 ensures decentralized actions in the face of the prevailing concentration of power, and clearly states the basic principles currently being practiced in almost all countries that lead the way in water resources management, namely: (i) use of catchment basin as a planning unit; (ii) multiple use of water; recognition of water as a finite and vulnerable good; and (iii) decentralized and participatory management.

Executive Order \# 2.123-27 of 27 December 2000, which is regularly reissued, amends the provisions of Law \# 9.649 of 27 May 1998, which organizes the Presidency of the Republic and the Ministries, grants powers to the water resources area, and establishes the respective scope of action, comprising: a) Ministry of Environment; b) Ministry of National Integration; c) Ministry of Agriculture and Food Supply; d) Ministry of Mines and Energy; e) Ministry of Transport; f) Ministry of Defense; g) Ministry of Health; h) Ministry of Science, Technology, Innovation and Communications; i) Ministry of Planning, Budget and Management; and j) Ministry of Foreign Relations.

The Ministry of Science and Technology, Innovation and Communications (MCTI) has a focus on the national scientific and technological research policy and planning, coordination, supervision, and control of scientific and technological activities.

\section{REDE DE SANEAMENTO E ABASTECIMENTO DE ÁGUA \\ (WATER SUPPLY AND SANITATION NETWORK - RESAG)}

'Sibratec' is the Brazilian Technology System established by Decree 6259 of November 2007 as a program of MCTI aiming to promote an approximation of the scientific and technological community with the businesses community, especially micro-, small- and medium-sized enterprises (MSMEs). It is organized into three components: innovation centers, technological services and technological extension [8].

As part of the governmental program Sibratec in 2011, and convergent with its goals, Rede de Saneamento e Abastecimento de Água (national Water Supply and Sanitation Network-RESAG) [9] was created as one element of the Technological services component. Its objective is the improvement of laboratories and technology development quality, to meet market demands in sanitation and water supply. Its activities during the first phase were related to laboratory tests and analyses, calibration, technical and management capacity, interlaboratory comparison programs, production of standards and certified reference materials, peer review, accreditation, consultancy, development of new materials, quality management, and related activities.

The purpose and key directions of RESAG strategy is to address water in a holistic manner, incorporating social, economic and environmental aspects, management, and use, involving partners from government, industry, academy, regulators, inspectors, auditors, nonprofit organizations, and other stakeholders. The interaction between institutional participants provides valuable insights in the context of institutional research, innovation, application, and quality improvement for the technological services offered to the society.

RESAG consolidated its basic structure (see Fig. 1), comprising 37 laboratories of 19 institutions from 10 Brazilian states distributed in the North, Northeast, South and Southeast regions. Its structure involves 310 researchers, as well as technicians developing projects in the field of: management, training, analytical competence, accreditation, proficiency testing, certified reference materials production, calibration, and materials for sanitation. 


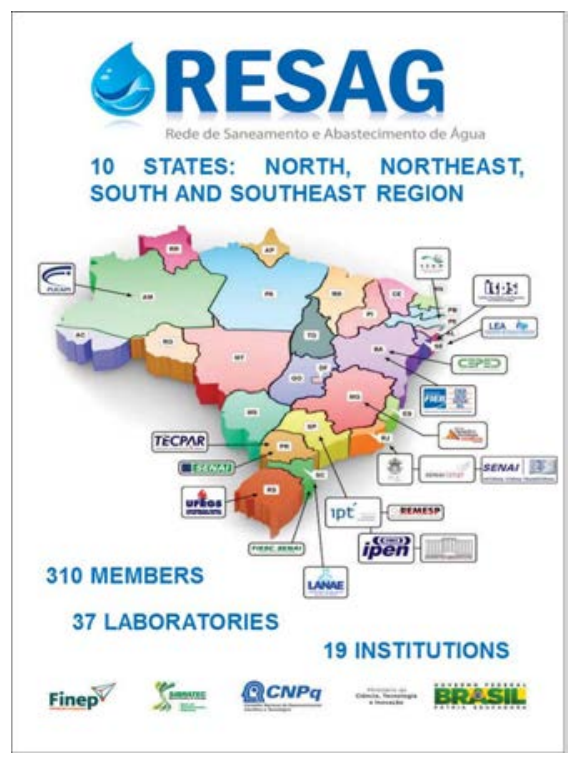

Figure 1: RESAG members in Brazil States.

Regarding activities, RESAG has developed services and products on: certified reference materials of cations and anions in water; interlaboratory comparison studies; proficiency testing; standardization; support for accreditation; human resource capacity; development of new materials for water supply; promotion of international congresses; and dissemination of the metrological culture in different ways.

Actions providing support for getting reliable measurement results are focused on RESAG activities. In this context, certified reference materials (CRMs) are used in the development and validation of methods, calibration of apparatus, quality control of goods production systems and materials, assigning values to materials, as well as assuring the integrity and reliability throughout the measurement process. By these functions, CRMs constitute an important mechanism for the establishment of metrological traceability. Comparable analytical results, for any time and place that have their traceability established according to international standards, constitute a strong base to quality control, which counts towards comparability of laboratory results throughout time and space.

The aim of developing Proficiency Testing/Interlaboratory Comparison Programs is to evaluate and demonstrate the reliability of laboratory results. The participation in those programs is important for the laboratories, allowing self-evaluation, and to demonstrate the laboratory competence to authorities, customers or partners [10]. They are required for the accreditation process, according to the ABNT NBR ISO/IEC 17025 standard.

An example of culture promotion and dissemination within RESAG activities is events organization, such as the Third International Congress, with the goal of providing an interaction space among corporate, government, and scientific communities, both at national and international levels. In this event, topics regarding planning and execution of public policies are the main topics, associated with several aspects of water resources, such as: integrated management, Waters Act, river basins, water resource plans, sanitation, water supply and use, in addition to environment and water crisis confrontation, thus providing a rich panorama for knowledge and experience exchanges at a global level. 
Table 1: RESAG goals.

\begin{tabular}{|c|c|c|}
\hline Project & $\begin{array}{l}\text { Coordination } \\
\text { Institution/State }\end{array}$ & Goals achieved \\
\hline Management & $\begin{array}{l}\text { Rede Metrológica do } \\
\text { Estado de São Paulo } \\
\text { (Remesp)/São Paulo }\end{array}$ & $\begin{array}{l}\text { Network technical management, } \\
\text { comprising: continuous monitoring, } \\
\text { evaluation of technical capacity, } \\
\text { evaluation of market demand, promotion } \\
\text { of joint activities and projects, etc. }\end{array}$ \\
\hline $\begin{array}{l}\text { Capacity-building } \\
\text { courses }\end{array}$ & Remesp/São Paulo & $\begin{array}{l}\text { Sixty courses on quality, metrology, } \\
\text { statistics and uncertainty in } \\
\text { measurements, traceability, method } \\
\text { validation, project management, business } \\
\text { plan and others. }\end{array}$ \\
\hline Accreditation & Remesp/São Paulo & $\begin{array}{l}\text { Financial and technical support for } \\
\text { accreditation of (i) Testing and } \\
\text { calibration laboratories, (ii) Proficiency } \\
\text { testing provider and (iii) Certified } \\
\text { reference materials producer. }\end{array}$ \\
\hline $\begin{array}{l}\text { Proficiency } \\
\text { testing }\end{array}$ & $\begin{array}{l}\text { Senai-Cetind/Bahia } \\
\text { and Remesp/São } \\
\text { Paulo }\end{array}$ & $\begin{array}{l}\text { Eight proficiency testing programs } \\
\text { rounds on metals in water, pH, } \\
\text { electrolytic conductivity, weighing at } \\
\text { analytical scales, physical chemistry } \\
\text { essays and water organoleptic properties. }\end{array}$ \\
\hline $\begin{array}{l}\text { Certified } \\
\text { reference } \\
\text { materials } \\
\text { production }\end{array}$ & $\begin{array}{l}\text { Instituto Adolfo } \\
\text { Lutz/São Paulo }\end{array}$ & $\begin{array}{l}\text { Production of certified reference } \\
\text { materials in water matrix for parameters } \\
\text { such as fluoride, nitrate, arsenic, } \\
\text { cadmium, lead, copper, iron, manganese } \\
\text { and zinc for drinking water levels. }\end{array}$ \\
\hline Calibration & $\begin{array}{l}\text { Instituto de } \\
\text { Tecnologia do } \\
\text { Paraná }\end{array}$ & $\begin{array}{l}\text { Improvement of the calibration services } \\
\text { in the field equipment and } \\
\text { implementation of new ranges and types. }\end{array}$ \\
\hline $\begin{array}{l}\text { Materials for } \\
\text { sanitation } \\
\text { characterization }\end{array}$ & $\begin{array}{l}\text { Federal University of } \\
\text { Rio Grande do Sul }\end{array}$ & $\begin{array}{l}\text { Methodologies, testing methods and } \\
\text { techniques for developing new materials } \\
\text { for water supply - polyethylene tubes. }\end{array}$ \\
\hline
\end{tabular}

\subsection{RESAG as a network}

Cooperative activities like networks are especially beneficial. This comes from the breadth of demands in chemical and biological metrology. In a network system such as RESAG, those demands can be solved with less investment, in a timely manner, following global standards [11]. However, networks system management requires careful oversight of all factors that affect its performance and maintenance, including those factors required for its improvement. RESAG is an important governmental initiative in a fundamental matter "Water", that requires scientific efforts to preserve this natural but limited resource.

In this scenario, one can consider the identification of benefits derived from performance in cooperative manner, based on the technical and scientific knowledge formed by the 
competences conjugation, both in human resources and in material and institutional infrastructure, as an important contribution. It is a way to accomplish researches, generate technological products, disseminate the culture and create dynamic and synergetic environments, highly specialized and up-to-date knowledge; acting according to world precepts from the best management practices with a critical vision regarding the state of practice and the state of art.

\section{WATER QUALITY, HEALTH, STANDARDS AND REGULATION}

Water quality refers to organic and inorganic chemicals, physical properties, and biological and radiological characteristics of water. It is necessary to have metrological reference and materials to measure those parameters, as well as a set of standards against which the compliance can be assessed.

It is fundamental to define which parameters are the most useful to support management decisions. They rely on technical-scientific statements, reliable laboratory results and policy decisions, considering factors such as enforcement capacity and costs. Parameters providing the highest protection are those having scientific evidence and directly related to public health, like those associated with fecal coliforms, Escherichia coli (E. coli), helminth eggs and organic matter.

In Brazil, resolutions by the National Environmental Council (CONAMA) are the framework for environmental public policies. These resolutions comprise a group of water quality regulations that have been implemented in Brazil since 1986, complemented by successive instruments over subsequent years to address requirements related to use and pollution control of surface and groundwater resources.

For environmental protection, the parameters include those regarding nutrients measurement and ecotoxicology standards. According to the World Health Organization [12], among the 102 major diseases which were covered by the World Health Report in 2004, environmental risk factors contributed to disease burden in 85 categories. Diarrheal disease was included in these categories, being estimated that $88 \%$ of the diarrhea burden of disease is attributable to environment and associated with risk factors, such as unsafe drinking water and poor sanitation and hygiene [13].

\section{DRINKING WATER REGULATION}

Owing to the large number of different chemicals that might be found in drinking water, it is virtually impossible to regulate all compounds [14]. This is because only limited or no toxicological data is available for most substances [15].

Therefore, for drinking water, the parameters and limits in Brazil are set by legislation according to Portaria 2914:2011, which defines standards, parameters and limits [16].

Drinking water quality control became itself an action of public health from the 1970s, when Norm 52 BSB 77, through the Ministry of Health, stated the water supply drinkability standard in all country. However, the realization of a drinking water surveillance program alone occurred from the creation of the National System of Environmental Health Surveillance (ANVISA) in 1999.

In this context, for drinking water, the parameters and limits in Brazil are set by legislation, currently according to Ordinance 2914:2011 which defines standards, parameters and limits that should guarantee safe drinking water for human consumption, according to quality control in microbiological, physical, chemical and radioactive elements measurement.

Standards must be "fit for purpose" to have water security and keep the people healthy not less parameters than required that could incur in diseases, not more than required, that 
will demand higher investments. Each country has its own scenery and regional factors that can affect human health. Then, the determination of suitable standards that effectively meet their objectives and have the right protection level is the critical point.

RESAG has developed proficiency testing programs to evaluate parameters of Ordinance 2914:2011 according to this perspective. The support provided for the measurement process benefits the participating laboratories, and acts as an objective component of total quality control, and as a self-improvement tool, supporting the implementation of regulatory requirements.

It is strategic to have national measurement systems to monitor the quality parameters and measure the efficiency of the sanitation process and other activities for an adequate management of this area, providing a reliable database of the national water quality. In this direction, the national Water Supply and Sanitation Network operates continuously for the improvement of the national laboratory basis, thus contributing to implementation of policies and regulations aiming at human health.

\section{CONCLUSIONS}

Many players are required to cover this area of sanitation and water supply, especially in Brazil, a country with continental dimensions and a very large diversity of regional conditions and needs, high differences between social classes and extremely poor people. Cooperative actuation has been shown especially beneficial in RESAG development, covering current demands in a timely manner, using national experts and equipment, and following global standards. In this context, the decision of the Brazilian Ministry of Science, Technology, Innovation and Communication in setting up networks like RESAG has showed to be adequate, as an effective technological practice for covering national needs.

Legislation and regulation must be very precise to establish what is necessary to keep a high-water quality standard and countries must attend those needs as it impacts human well-being, environment and national economy.

Making water management more efficient through innovative and wise policies and regulations, supported by a national laboratory measurement system is a way to get feasible and have the right implementation of this area.

Guaranteeing water security is a complex endeavor, requiring strict water quality control, involving aspects of implementation, monitoring, classification, and evaluation. As this question is not limited to one or another country, it must be treated as a global issue, demanding urgent solutions at all levels, from the local to the global.

Convergent to the worldwide concern and Sustainable Goals for Development, accessible quality water is essential to live and it must be avoiding situations where every year millions of people, most of them children, die from diseases coming from inadequate hygiene, sanitation and water supply. Besides the consumption, by managing water sustainably, countries will be able to better manage the production of food, environmental protection, energy, preserving water ecosystems, and contributing to competitiveness and a better society.

\section{ACKNOWLEDGEMENTS}

For the development of this work, the authors thank the Sibratec Program of the Brazilian Ministry of Science, Technology, Innovation and Communication, the Financiadora de Estudos e Projetos (Brazilian Innovation Agency), FINEP, and the Brazilian National Council for Scientific and Technological Development (CNPq). 


\section{REFERENCES}

[1] Sustainable Development Agenda by 2030; Ensure Access to Water and Sanitation for All; United Nations, Online. http://www.un.org/sustainabledevelopment/water-andsanitation/. Accessed on: 5 May 2017.

[2] Projeções E Estimativas Da População Do Brasil E Das Unidades Da Federação; Fundação Instituto Brasileiro Geografia Estatística, Online. http://www.ibge.gov.br/home/. Accessed on: 4 May 2017.

[3] Water Resources Management in Brazil; Agência Nacional de Águas, Online. hidroweb.ana.gov.br/cd2/water/docs/part2.htm. Accessed on: 30 Apr. 2017.

[4] Food and Agriculture Organization of the United Nations, Chapter 3: Fertilizers as Water Pollutants. FAO Corporate Document Repository, Rome, 1996.

[5] Santos, I.S. et al., Infant mortality in three population-based cohorts in Southern Brazil: trends and differentials. Cadernos de Saúde Pública, 24(suppl 3), pp. S451-460, 2008.

[6] Freitas, D.H. et al., Evaluation of water quality parameters for monitoring natural, urban, and agricultural areas in the Brazilian Cerrado. Acta Limnologica Brasiliensia, 23(3), 2011. ISSN 2179-975X.

[7] World Health Organization, Meeting on the Drinking Water and Sanitation: The Urban and Rural Challenge of the Decade, Regional and Global status in 1990 and 2004; 2007, Online. http://www.who.int/water_sanitation_health/monitoring/jmpfinal.pdf. Accessed on: 29 Apr. 2017.

[8] Wikipedia; The Free Encyclopaedia, Water Supply and Sanitation in Brazil, Online. https://en.wikipedia.org/wiki/Water_supply and sanitation_in_Brazil. Accessed on: 20 Apr. 2017.

[9] Reunião de Estruturação das Redes Sibratec de Serviços Tecnológicos; Sistema Brasileiro de Tecnologia Sibratec, March 30 and 31, 2009, Online. ftp://ftp.mct.gov.br/Unidades/SETEC/CGST/COTB/Apresentacoes/Apresentacao

SecretarioSETEC ReuniaoSIBRATEC.pdf. Accessed on: 15 Mar. 2017.

[10] Rede De Saneamento E Abastecimento De Água, Online. www.resag.org.br. Accessed on: 2 May 2017.

[11] Plonski, G.A. \& Ponçano, V.M.L., Programa Brasileiro De Metrologia Em Química: Gerando Redes De Tecnologia Industrial Básica. Proceedings of the 23th Simpósio de Gestão de Inovação Tecnológica, pp. 2818-2830, 2004.

[12] Silva, V.M.L.P.A., Estudo de Organização Em Rede Na Metrologia Em Química. Tese de Doutorado, Instituto de Pesquisas Energéticas e Nucleares, Universidade de São Paulo, 2007.

[13] Fewtrell, L., Prüss-Üstüm, A., Bos, R., Gore, F. \& Bartram, J., Water, sanitation and hygiene: quantifying the health impact at national and local levels in countries with incomplete water supply and sanitation. WHO Environmental Burden of Diseases, Series no. 15, 2007.

[14] Prüss-Üstün, A. \& Corvalán, C., Preventing disease through healthy environments, World Health Organization, 2006.

[15] World Health Organization, Guidelines for Drinking-Water Quality, 4th edition, 2011.

[16] Ministério da Saúde; Portaria No. 2.914, de 12 de Dezembro de 2011. Dispõe sobre os procedimentos de controle e de vigilância da qualidade da água para consumo humano e seu padrão de potabilidade. SVS: Brazil, 2011. 